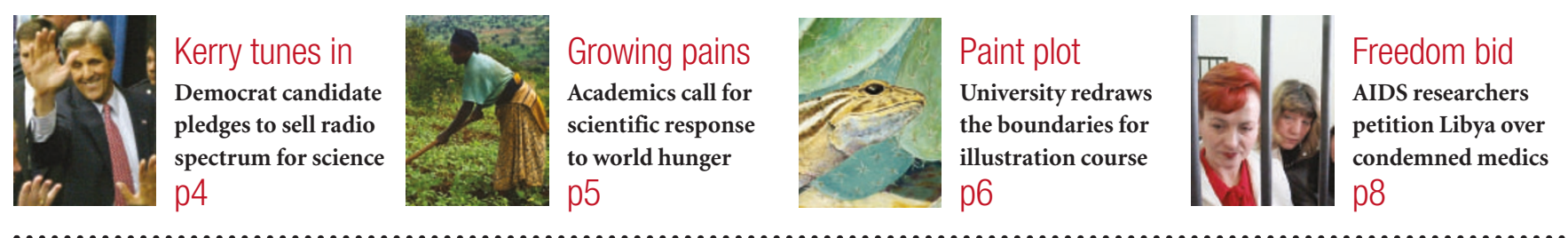

\title{
Earth science loses autonomy as NASA switches focus to the Moon
}

Tony Reichhardt, Washington

NASA is poised to undertake its most sweeping reorganization in more than a decade. The plan, announced on 24 June, will see the agency halve the number of offices at its headquarters, eliminate its Earth sciences directorate, and transfer several key personnel, including head of space science Ed Weiler, into new positions.

Sean O'Keefe, the agency's administrator, says that the streamlining will focus NASA more clearly on the Bush administration's priorities - particularly sending astronauts back to the Moon and on to Mars. But critics worry that the changes may marginalize the Earth sciences and reduce NASA's involvement in the politically contentious sphere of climate change.

From 1 August, NASA will be organized around four missions: exploration (the new Moon-Mars programme), space operations (including shuttle launches), science and aeronautics. Earth science will be lumped in with space science, but most of the microgravity research done on the International Space Station will fall under the exploration office.

In addition, the agency's ten field centres will report directly to a single mission directorate, rather than serving many masters as they do now. For example, three of the centres - Ames in Moffett Field, California; Goddard in Greenbelt, Maryland; and the Jet Propulsion Laboratory in Pasadena, California - will fall under the science mission.

In merging the Earth and space science programmes, O'Keefe undoes the work of his predecessor Dan Goldin, an appointee of the first president George Bush. Goldin dismantled the larger Office of Space Science and Applications in 1992 and elevated Earth science to an equal footing with space science.

Charles Kennel, director of the Scripps Institution of Oceanography in La Jolla, California, and chairman of the NASA Advisory Council, admits that "there are all these fears out there" that Earth science will suffer under the new organization. For example,
NASA Earth science may no longer have an obvious advocate in interagency discussions on climate research, he says.

Lori Garver, a former head of NASA's policy office and now vice-president at DFI International, a Washington consulting firm, agrees that merging Earth and space science makes the former's budget "easier to raid" without having to consult Congress. But NASA's budget for Earth science was in decline even before the reorganization, and O'Keefe adamantly denied last week that it would suffer as a result of the change.

\section{Strong advocate}

Scientists inside and outside the agency also decried the loss of Weiler from the top science spot at NASA. Known as a tough decision-maker and a strong, articulate advocate for science, he will move to head the agency's Goddard Space Flight Center.

Although Weiler admits the switch was not his idea, he discounts speculation in Washington that he is being moved after clashing with O'Keefe over the administrator's decision not to have astronauts service the Hubble Space Telescope (see Nature 428, 353; 2004). He says that O'Keefe wants him to manage the proposed Hubble robotic servicing mission, one of the agency's most challenging projects. He will take over a respected institution with more scientists than any other NASA centre, which has also just been given responsibility for the revitalized lunar science programme.

The new head of the merged Earth and space science directorate is Al Diaz, the current director of Goddard and a 40-year NASA veteran with senior management experience in Earth and space science. Diaz has strong ties with Senator Barbara Mikulski (Democrat, Maryland), who exerts a powerful influence on NASA's budget. But he is not a PhD scientist. Although Diaz has a solid managerial record, Berrien Moore, an Earth scientist at the University of New Hampshire and a frequent member of NASA advisory groups, asserts that "the head of NASA science needs to be a distinguished scientist". Nor has Diaz shown Weiler's flamboyance, or his flair for public relations. "He's not timid," says a former colleague, "but he's not as 'in-your-face' as Ed is."

However Earth and space science fare, the main purpose of the reorganization is to make the Moon-Mars programme a primary goal. Some critics question why NASA should make this change now, considering that Bush's plan got a lukewarm response in Congress and may not survive November's presidential elections. With NASA struggling to return the shuttle to flight, finish the International Space Station, and manage a full plate of science projects, there is "serious concern about confusion" if NASA's workforce now has to reorganize as well, claims one veteran agency observer.

But others say that a more streamlined agency makes sense. "Frankly, I like a lot of these changes," says Garver, adding that they should improve communication within the agency and help clarify its missions to outsiders. "The human exploration programme will be much better off," says Kennel, "and that's worth a lot to the agency, because half of its enterprise is human exploration." 